\title{
Vigencia de la participación política prohibida en servidores judiciales: una propuesta de reforma del artículo 9 de la Ley Orgánica del Poder Judicial y el146 del Código Electoral
}

\section{Daniela Lara Matarrita*}

https://doi.org/10.35242/RDE_2019_29_2

Nota del Consejo Editorial

Recepción: 11 de junio de 2019.

Revisión, corrección y aprobación: 18 de octubre de 2019.

Resumen: Los servidores del Poder Judicial se encuentran sujetos a distintas regulaciones en virtud del principio general del derecho administrativo de legalidad, bajo el cual solamente pueden actuar dentro del marco que la ley les habilita. Asimismo, deben acogerse a limitaciones y las que interesan en este artículo están referidas a la beligerancia política. A partir de ellas, la población judicial solamente puede participar en el sufragio activo el día de las elecciones y el goce del resto de derechos político-electorales les está vedado. Dichas prohibiciones resultan, actualmente, desactualizadas e inconvencionales (por ser violatorias de derechos fundamentales); y, por tanto, requieren ser modificadas mediante una reforma de ley. El presente texto pretende ser una exposición de motivos de lo que más adelante podría presentarse como un proyecto de ley tendiente a variar el contenido del artículo 9 de la Ley Orgánica del Poder Judicial y el artículo 146 del Código Electoral.

Palabras clave: Beligerancia política / Derechos políticos / Participación política / Prohibición / Funcionarios judiciales / Poder Judicial / Reforma a la ley / Reformas electorales.

Abstract: The Judiciary workers are subject to different regulations in accordance with the general principle of the Administrative Law of legality, which states that they can only act within the framework that the law grants them. Likewise, they must submit to limitations related to political belligerence, subject that will be discussed in this article. Therefore, the Judiciary workers can only exercise the right of suffrage on the day of national elections and the enjoyment of the rest of the politico-electoral rights is forbidden. Today, such prohibitions are outdated and unconventional (as violating fundamental rights); consequently, they should be eliminated by promoting a reform of the law. In this article, the author aims to state the motives for presenting a draft bill designed to modify an article of the Organic Law of the Judiciary and of the Electoral Code.

Key Words: Political belligerence / Political rights / Political participation / Prohibition / Judiciary employees / Judiciary Branch / Reform to the law / Electoral reforms.

\footnotetext{
* Costarricense, abogada, correo electrónico danilaram30@gmail.com. Licenciada en Derecho con mención en Formación de Jueces por la Universidad de Costa Rica. Especialista en Derecho Notarial y Registral de la Universidad Fidélitas y estudiante de la maestría profesional en Derecho Público de la Universidad de Costa Rica. Se ha desempeñado como consultora legal del Alto Comisionado de las Naciones Unidas para los Refugiados (ACNUR) en la Asociación de Consultores y Asesores Internacionales (ACAI), en la Dirección General de Migración y Extranjería y de la Organización Hebrea de Ayuda para Inmigrantes y Refugiados (HIAS Costa Rica), agencia implementadora del ACNUR. Actualmente, se desempeña como abogada del Área de Empleo Público del Departamento Legal del Tribunal Supremo de Elecciones.
} 


\section{DERECHO ELECTORAL}

\section{INTROducción: Colusión de NORMAS REFERENTES A BELIGerancia POLÍTICA PROHIBIDA}

En una investigación precedente, denominada "Restricción generalizada a la participación política de los servidores judiciales" (Lara y Sánchez, 2016), se concluyó que dicha prohibición para que los servidores del Poder Judicial participen en la contienda electoral más allá de la emisión del sufragio resulta, actualmente, desactualizada.

La investigación arriba a tal conclusión tras haber analizado cuidadosamente tres normas en particular, las funciones de las diferentes dependencias del Poder Judicial, la aplicación de entrevistas a expertos para valorar la constitucionalidad y convencionalidad de las restricciones y encuestas dirigidas a funcionarios para apreciar el conocimiento de sus derechos y su interés en la participación política.

En el presente artículo se expondrán los principales hallazgos de la referida investigación, sin embargo, incorpora la propuesta de reforma legal que en su momento sólo se había mencionado como una de las posibles cuatro alternativas para resolver la problemática expuesta, pero que, actualmente, se considera la opción más viable. Asimismo, se analizan otros factores, por los que conviene eliminar la restricción de participación política a la que están afectos los servidores judiciales. En dicho trabajo, concretamente, fueron estudiados el inciso 5) del numeral 102 constitucional, 146 del Código Electoral y los incisos 5) y 6) del artículo 9 de la Ley Orgánica del Poder Judicial (en adelante, "LOPJ"), todos referentes a la beligerancia política, pero con consideraciones más o menos restrictivas en sus respectivos textos.

La Carta Fundamental indica en el mencionado artículo lo siguiente:

El Tribunal Supremo de Elecciones tiene las siguientes funciones: (...)

5) Investigar por sí o por medio de delegados, y pronunciarse con respecto a toda denuncia formulada por los partidos sobre parcialidad política de los servidores del Estado en el ejercicio de sus cargos, o sobre actividades políticas de funcionarios a quienes les esté prohibido ejercerlas. La declaratoria de culpabilidad que pronuncie el Tribunal será causa obligatoria de destitución e incapacitará al culpable para ejercer cargos públicos por un período no menor de dos años, sin perjuicio de las 


\section{DERECHO EIECTORAL}

responsabilidades penales que pudieren exigírsele. No obstante, si la investigación practicada contiene cargos contra el Presidente de la República, Ministros de Gobierno, Ministros Diplomáticos, Contralor y Subcontralor Generales de la República, o Magistrados de la Corte Suprema de Justicia, el Tribunal se concretará a dar cuenta a la Asamblea Legislativa del resultado de la investigación.

Como puede verse la Constitución Política hace alusión a la imposibilidad de mostrar parcialidad política dentro de la Administración Pública; sin embargo, no queda claro bajo cuáles puestos recae la prohibición, ya que únicamente especifica ante cuál órgano se ventilarán los procesos que involucren a funcionarios del Estado de alta jerarquía.

Por su parte, el ordinal 9 de la LOPJ se refiere a la imposibilidad de participación de los servidores del Poder Judicial, restricción que se aplica de forma generalizada según los siguientes incisos:

\section{$(\ldots)$}

5.- Cualquier participación en procesos políticos electorales, salvo la emisión de su voto en elecciones generales.

6.- Tomar parte activa en reuniones, manifestaciones y otros actos de carácter político electoral o partidista, aunque sean permitidos a los demás ciudadanos.

\section{$(\ldots)$}

Finalmente, el texto del Código Electoral vigente es el que crea mayor confusión al mantener en el numeral 146 lo que establecía el artículo 88 del código anterior, el cual pareciera dejar fuera de la limitación a una parte de la población judicial, pues reza lo siguiente:

Prohíbase a los empleados públicos dedicarse a trabajos o discusiones de carácter político-electoral, durante las horas laborales y usar su cargo para beneficiar a un partido político. Los jefes inmediatos de dichos empleados serán los responsables de vigilar el cumplimiento de esta disposición. Quienes ejerzan la Presidencia o las Vicepresidencias de la República, los ministros (as) y viceministros (as), y los miembros activos o las miembros activas del servicio exterior, el contralor o la contralora y 


\section{DERECHO EIECTORAL}

Subcontralor o Subcontralora generales de la República, el (la) defensor (a) y el (la) defensor (a) adjunto (a) de los habitantes, el (la) procurador (a) general y el (la) procurador (a) general adjunto (a), quienes ejerzan la presidencia ejecutiva, o sean miembros (as) de las juntas directivas, directores ejecutivos, gerentes y subgerentes de las instituciones autónomas y todo ente público estatal, los (as) oficiales mayores de los ministerios, los (as) miembros (as) de la autoridad de policía, los (as) agentes del Organismo de Investigación Judicial (OIJ), los magistrados (as) y toda persona empleada del TSE, los magistrados y funcionarios (as) del Poder Judicial que administren justicia, y quienes tengan prohibición en virtud de otras leyes, no podrán participar en las actividades de los partidos políticos, asistir a clubes ni reuniones de carácter político, utilizar la autoridad o influencia de sus cargos en beneficio de los partidos políticos, colocar divisas en sus viviendas o vehículos, ni hacer ostentación partidista de cualquier otro género. En materia electoral, las personas funcionarias incluidas en el párrafo segundo de este artículo, únicamente podrán ejercer el derecho a emitir su voto el día de las elecciones en la forma y las condiciones establecidas en este Código. EI TSE podrá ordenar la destitución e imponer inhabilitación para ejercer cargos públicos por un período de dos a cuatro años, a los funcionarios citados, cuando sus actos contravengan las prohibiciones contempladas en este artículo.

De la lectura cuidadosa del numeral anterior puede extraerse que la restricción impuesta recae sobre los servidores del Poder Judicial que administran justicia y los agentes del Organismo de Investigación Judicial, y no como señala el ordinal de la LOPJ a toda la población judicial. Cabe preguntarse, entonces, cuál es la norma que impera y si la otra debe ser eliminada del ordenamiento jurídico.

Para tratar de dar respuesta a tal interrogante, se revisaron alrededor de dieciséis mil folios correspondientes a las actas legislativas ${ }^{1}$, a fin de

\footnotetext{
${ }_{1}^{1}$ Asamblea Nacional Constituyente de 1949. Acta No.74: 24 de mayo de 1949. Asamblea Nacional Constituyente de 1949. Acta No.75: 25 de mayo de 1949. Asamblea Nacional Constituyente de 1949. Acta No.76: 26 de mayo de 1949. Asamblea Nacional Constituyente de 1949. Acta No.100: 01 de julio de 1949. Asamblea Legislativa, Área de Actas, Sonido y Grabación. Acta Legislativa No. 53, Sesión del 10 de agosto de 2009.
} 


\section{DERECHO EIECTORAL}

conocer el espíritu del constituyente y el legislador para cada caso. De ahí, se desprendió que la restricción de participación política respondió a un contexto histórico en el que imperaba la desconfianza respecto de los funcionarios públicos y el trámite de los procesos electorales. Se pretendía, entonces, con esas disposiciones impedir actos de corrupción durante los comicios. Garantizar esa pureza electoral y convertirse en un modelo de democracia fueron los objetivos que durante un complejo proceso histórico impulsaron a la jurisdicción electoral para que cada vez fuera más técnica, ordenada, transparente y confiable. (Lara y Sánchez, 2016).

A partir del estudio se confirmó que la disposición constitucional quedó abierta a la interpretación, pues solamente limita en el sentido de que no se pueden llevar a cabo actividades de carácter político-electoral durante el horario de trabajo ni utilizar los recursos públicos para ello, lo cual resulta absolutamente lógico.

Por su parte, el Código Electoral dirigió la prohibición a funcionarios de altos rangos $\mathrm{y}$, dentro del Poder Judicial, específicamente, se refirió a los administradores de justicia, pero la LOPJ limitó de forma absoluta la participación de los servidores judiciales, quienes solamente pueden acceder al sufragio activo.

\section{TESis DE LA DEROgATORIA TÁCITA}

Las tres normas señaladas, continúan estando vigentes en el ordenamiento jurídico costarricense, a pesar de que se ha cuestionado si podría existir una derogatoria tácita de los incisos del ordinal 9 de la ley a partir de la publicación del Código Electoral de 2009, y con ello la confirmación de la corriente en la que se limitaba solamente a ciertos funcionarios (Lara y Sánchez, 2016).

Lo anterior porque al estudiar en orden cronológico el cuerpo de prohibiciones, iniciando con la LOPJ publicada en 1937, posteriormente el contenido de la Carta Fundamental del 49 y por último el Código Electoral

Asamblea Legislativa, Comisión Especial de Reformas Electorales y Partidos Políticos. Expediente No. 16212. Acta Legislativa No. 86, Sesión extraordinaria del 24 de junio de 2009.

Asamblea Legislativa. Exposición de Motivos del Proyecto de Ley del Código Electoral. Acta Legislativa No. 27, (s.f.) 


\section{DERECHO ELECTORAL}

vigente, se advierte una discordancia que podría conllevar la supresión parcial de lo dispuesto en la primera.

De ahí puede contemplarse la posibilidad de que la norma especial y posterior provoque la cesación de la norma anterior por incompatibilidad objetiva, sobre todo porque se encuentra ante una contrariedad en el tratamiento de derechos fundamentales como lo son los derechos políticoelectorales. De hecho, si se examinan las regulaciones indicadas en el orden dicho, puede notarse que ha habido una tendencia a ser cada vez menos restrictiva, lo cual, a mi criterio, es consecuente con una apertura y respeto por los derechos fundamentales cada vez más imperantes en los países que se consideran Estados de derecho, independientemente de los sistemas existentes para la aplicación de las normas en el tiempo, que en su mayoría se rigen por metodologías meramente positivistas

Debe recordarse que, si bien, en doctrina se han definido métodos para determinar la aplicación de las normas en el tiempo y la prevalencia de una sobre otra, tales como la de la ley posterior y ley especial, no es un ejercicio que se pueda dar en automático, pues como bien señala la Sala Primera en el voto 928-2010 del 05 de agosto de 2010, al detectarse una antinomia, les corresponde a los operadores jurídicos realizar la interpretación correspondiente.

Además, no puede dejarse de lado que al ser los derechos políticoelectorales parte de la gama de derechos fundamentales, la interpretación debe ser aún más cuidadosa, de manera que se resuelva la posible antinomia, pero también se tutele el disfrute de las garantías contempladas constitucionalmente y en los instrumentos internacionales ratificados por Costa Rica.

Ahora bien, para que opere la derogatoria tácita mencionada se requiere que haya habido una constatación técnica por parte de un órgano competente para ello. Realizado ese análisis, se podrían definir los alcances de la nueva disposición. No obstante, dicha constatación no ha ocurrido para el caso concreto, pues el Tribunal Supremo de Elecciones (en adelante "TSE") supone que la normativa es clara en señalar que ningún servidor judicial puede participar en actividades de carácter político-electoral, independientemente de si administran justicia o no.

Así lo indicó el órgano electoral mediante resolución número 472-E8-2008 de las 7:50 horas del 13 de febrero de 2008: 


\section{DERECHO ELECTORAL}

Conforme se aprecia, esta norma [referido a los incisos 5 y 6 del numeral 9 de la Ley Orgánica del Poder Judicial] es una adaptación, a lo interno de la Ley Orgánica del Poder Judicial, del artículo 88 del Código Electoral [la numeración según el código actual es 146], con la diferencia de que amplía la cobertura de la prohibición. Es decir, el impedimento establecido por los comentados artículos del Código Electoral, para los funcionarios judiciales que administran justicia, lo extiende -por norma de posterior promulgación- a los funcionarios que no administran justicia y, en general, a los empleados de ese Poder de la República. Ampliación que, además de marcar la diferencia entre lo dispuesto por el Código Electoral y por la Ley Orgánica del Poder Judicial, ha sido sobradamente analizada por la jurisprudencia, tanto de la Sala Constitucional, como de esta Autoridad Electoral. No existiendo razón para variar el criterio sostenido en la jurisprudencia referida, resulta ocioso detenerse en este punto.

A pesar de lo anterior, en el estudio mencionado no se coincidió, y se sigue discrepando, con la opinión del TSE, pues se identificó la existencia de una antinomia entre los artículos y la necesidad de buscar una actualización que permitiera a los funcionarios judiciales acceder al resto de derechos de índole política-electoral (Lara y Sánchez, 2016).

\section{TEORÍA FUNCIONARIAL Y CAPACIDAD DE INCIDENCIA EN LA CONTIENDA ELECTORAL}

En razón de que los derechos políticos comprenden mucho más que el derecho al voto, además, se incluyen en ellos libertades como la de expresión, reunión, asociación, garantías judiciales y difusión (sin pretender hacer una lista taxativa), pareció conveniente examinar propuestas de restricción solamente sobre determinados puestos. Todo esto con el objetivo de habilitar a una gran cantidad de servidores judiciales que se consideró no tenían ninguna posibilidad de incidir en la contienda electoral a través de sus labores, pues son meramente administrativas o de trámite $y$, por tanto, sin la posibilidad de influenciar de forma alguna el proceso.

En virtud de lo anterior, se revisaron cuidadosamente las ocupaciones de cada uno de los despachos de los tres ámbitos (administrativo, judicial y auxiliar de la justicia) del Poder Judicial, a efectos de determinar la posible 


\section{DERECHO ELECTORAL}

injerencia de un funcionario judicial en el proceso electoral y, por ende, la necesidad de mantener o no la prohibición existente.

También se aspiró a conocer la posición de los servidores acerca del contenido de los derechos político-electorales y su acceso como funcionarios de la institución, su deseo de participar, la posible repercusión en la neutralidad del proceso electoral, si las prohibiciones deberían operar según el cargo y la opinión general sobre las limitaciones. Dicha revisión se hizo mediante dos vías, una de carácter deductiva (consulta bibliográfica, normativa y jurisprudencial) y otra inductiva por medio del uso de instrumentos de investigación (encuestas a expertos y entrevistas aplicadas a una muestra del conglomerado judicial). Mediante el procedimiento, se pudo confirmar que de los 11454 servidores judiciales que laboraban para el Poder Judicial en el año 2016, la porción de servidores judiciales que desempeñan labores meramente administrativas es bastante importante y no se localizan solamente en el ámbito administrativo, pues dentro del jurisdiccional y auxiliar de la justicia también hay puestos de esa índole.

Por otro lado, la intención de entrevistar a los servidores fue verificar si el conglomerado judicial era consciente de lo que significa la restricción y si, a pesar de ella, presentaban interés en ejercer sus derechos políticoelectorales distintos del sufragio, pues siendo a ellos a quienes les afecta, lo lógico era confirmar que lo perciben como una lesión a sus derechos fundamentales.

Del ejercicio realizado se extrajo que entre el $72,2 \%$ y el $92,9 \%$ de servidores judiciales (según cada uno de los ámbitos de la institución) tiene interés de participar en otras actividades (agruparse en partidos políticos, reunirse a discutir asuntos políticos, tener acceso a las funciones públicas, intervenir en asuntos sometidos a referéndum, acudir a las sesiones de los órganos legislativos y deliberantes, etc.). A pesar de lo anterior, fue un pequeño grupo de funcionarios encuestados el que contestó atinadamente acerca del conocimiento de sus derechos político-electorales y a cuáles concretamente tienen acceso o no según las imposiciones que les establece su ley orgánica.

Por otro lado, como parte de las conclusiones obtenidas de la encuesta, se consideró que las limitaciones establecidas impiden que personas con gran capacidad se involucren en la toma de decisiones y se postulen como candidatos a puestos de elección popular; asimismo, que las restricciones 


\section{DERECHO ELECTORAL}

podían contribuir a que los funcionarios terminaran perdiendo el interés en participar en los procesos electorales (Lara y Sánchez, 2016).

Respecto a las entrevistas realizadas a los expertos ${ }^{2}$, lo que se pretendía era definir la relación entre las competencias y las prohibiciones, la posible incidencia por parte de los servidores judiciales en la contienda, vigencia y constitucionalidad de la beligerancia política prohibida y si la restricción consiste en una trasgresión refleja a los derechos fundamentales de dicha población.

\section{INCONSTITUCIONALIDAD E INCONVENCIONALIDAD DE LAS NORMAS SOBRE BELIGERANCIA POLÍTICA PROHIBIDA}

Sobre la inconstitucionalidad de las limitaciones de comentario, la Sala Constitucional ha manifestado:

Si bien la Constitución Política consagra los derechos y deberes políticos (artículos 90 y siguientes), los derechos de asociación (artículo 25) y reunión (artículo 26), de conformidad con la reiterada jurisprudencia de la Sala, el ejercicio de los derechos fundamentales no es ilimitado. El legislador puede introducir limitaciones a dichos derechos, siempre y cuando, éstas sean justificadas, razonables, proporcionadas y no lesionen el contenido esencial de aquellos. (...)

De manera que, al igual que los otros derechos fundamentales, el derecho de reunión y en general el de participación en los procesos político-electorales, también son susceptibles de limitaciones impuestas por el legislador, quien constitucionalmente está facultado para regular el modo de ejercicio de éstos, máxime cuando como en el caso bajo examen, están de por

\footnotetext{
${ }^{2}$ Luis Diego Brenes Villalobos, Licenciado en Derecho y Notario Público de la Universidad de Costa Rica, Máster en Derecho Constitucional de la Universidad Estatal a Distancia (UNED), Costa Rica, Especialista en Derecho Constitucional de la Universidad de Salamanca, España, Doctor en Ciencia Políticas de la Universidad de Salamanca, España; Magistrado del Tribunal Supremo de Elecciones y docente de la Facultad de Derecho de la Universidad de Costa Rica.

Ricardo Salas Porras, Bachiller en en Ciencias Criminológicas. Universidad Estatal A Distancia, Licenciado en Derecho, Universidad de Costa Rica, Máster en Ciencias Políticas. Universidad de Costa Rica, Doctor en estudios de la Sociedad y la Cultura, Universidad de Costa Rica; Letrado de la Sala III de la Corte Suprema de Justicia y Director del Área de Investigación de la Facultad de Derecho de la Universidad de Costa Rica.

Oscar Hernández Cedeño, Licenciado en Derecho de la Universidad de Costa Rica, Máster en Administración de Negocios del Instituto Tecnológico de Costa Rica; con amplia experiencia como asesor legislativo y docente de la Facultad de Derecho de la Universidad de Costa Rica
} 


\section{DERECHO EIECTORAL}

medio los rasgos definitorios intrínsecos a la naturaleza de la función judicial del Estado y los deberes de los servidores públicos que laboran para el Poder Judicial. (Sala Constitucional, 2014, resolución número 868-2014).

Al revisarse la constitucionalidad de las normas, se concluyó que, si bien no rozan con la Carta Fundamental, la disposición de la LOPJ sí deviene en inconvencional, pues hay un uso extralimitado del margen de apreciación y, por ende, una lesión a derechos fundamentales, en este caso, los políticoelectorales (Lara y Sánchez, 2016).

Ahora bien, es claro que el legislador está en capacidad de establecer restricciones a los derechos, pero estas no pueden llegar a vaciarlos de contenido y menos aun cuando se trata de derechos fundamentales de carácter político electoral, pues los derechos político-electorales no se resumen al ejercicio del voto, sino que incluyen el sufragio pasivo como activo, derecho a formar partidos políticos, a ejercer cargos públicos, libertad de expresión, de reunión y manifestación y a la participación política. Además, como ha indicado la Corte Interamericana de Derechos Humanos (en adelante, "Corte IDH") los impedimentos son plausibles cuando pretenden la seguridad nacional, preservar las libertades, el orden y la moral pública.

En vista de la problemática expuesta, se plantearon en aquel momento cuatro alternativas ante la discordancia de normas. El análisis de constitucionalidad ante la Sala Constitucional, la solicitud de opinión consultiva ante el TSE como intérprete exclusivo y excluyente de la materia, la reforma legal mediante una fórmula sencilla y, finalmente, acudir ante la Corte IDH.

La primera propuesta, sin embargo, presenta el inconveniente de que para tener por finalizada la contraposición de normas de manera definitiva, se requeriría una sentencia claramente interpretativa, cuando lo correcto es que el Tribunal Constitucional se pronuncie positiva o negativamente sin dimensionar efectos (Lara y Sánchez, 2016). Además, como se señaló, la Sala Constitucional ha declarado en jurisprudencia reiterada que no encuentra problemas en la interpretación acerca de qué o cómo debe aplicarse ni que se trate de un problema de constitucionalidad, por lo que esta opción no pareciera ser la que resuelva el conflicto de las normas aludidas, al menos hasta la fecha. 


\section{DERECHO EIECTORAL}

Con respecto a la consulta al TSE, es la vía por la que se apostó con anterioridad, sin embargo, cabe mencionar que recientemente se presentó una por parte de una funcionaria judicial y fue rechazada prácticamente ad portas. El voto reiteró la posición de que no hay confusión respecto de la aplicación de las normas; este manifestó:

En efecto, este Pleno ha señalado que, a todos los servidores judiciales, independientemente de si administran justicia o no, les alcanza una prohibición absoluta para participar en actividades político electorales. Según el ordenamiento jurídico costarricense, tales funcionarios solo tienen derecho a emitir el voto el día de las elecciones. (Tribunal Supremo de Elecciones, 2018, resolución número 1728-E8-2018).

Asimismo, continuó declarando el TSE la inexistencia de una derogatoria tácita y más bien hizo alusión a que el Código confirma la imposibilidad de participación al señalar:

De esa suerte, las normas contenidas en los incisos 5 y 6 del artículo 9 de la Ley Orgánica del Poder Judicial no deben entenderse tácitamente derogadas por el ordinal 146 del Código Electoral sino, más bien, su vigencia fue reafirmada al señalarse -en ese artículo- que: "quienes tengan prohibición en virtud de otras leyes, no podrán participar en las actividades de los partidos políticos, asistir a clubes ni reuniones de carácter político, utilizar la autoridad o influencia de sus cargos en beneficio de los partidos políticos, colocar divisas en sus viviendas o vehículos, ni hacer ostentación partidista de cualquier otro género. (Tribunal Supremo de Elecciones, 2018, resolución número 1728-E8-2018).

En relación con la inconvencionalidad es importante mencionar que la Corte IDH, fue enfática en el caso Castañeda Gutman contra México, respecto de las causales taxativas contenidas en el artículo 23 de la $\mathrm{CADH}$, a través de las que se puede restringir el uso de los derechos contenidos en el párrafo 1 , de manera que se evite toda discriminación a los individuos en el ejercicio de aquellos.

En palabras de este alto tribunal "se trata de límites que legítimamente los Estados pueden establecer para regular el ejercicio y goce de los derechos políticos y que se refieren a ciertos requisitos que las personas titulares de los derechos políticos deben cumplir para poder ejercerlos". (Corte 


\section{DERECHO ELECTORAL}

Interamericana de Derechos Humanos, 2008). De ahí que se haya considerado la inconvencionalidad de la norma, ya que a mi criterio las restricciones bajo análisis trascienden los límites establecidos por la norma $y$, por tanto, afectan los derechos fundamentales de la población judicial.

Sin embargo, acudir a cuestionar la inconvencionalidad de los incisos del ordinal 9 de la LOPJ ante la Corte IDH es un proceso muy complejo, pues inicialmente requiere pasar el examen de admisibilidad en la Comisión Interamericana de Derechos Humanos (en adelante "CIDH"), lo cual podría resultar sumamente engorroso y prolongarse por mucho tiempo. En virtud de lo anterior, pareciera que la solución es interrumpir la "suerte de comodidad" de los legisladores con la disposición, pues son los únicos que poseen la competencia para llevar a cabo la modificación necesaria a fin de eliminar la restricción y habilitar a los servidores judiciales en el goce del resto de sus derechos.

\section{Conclusión: Propuesta de reforma a los incisos 5 y 6 del artículo 9 de la Ley Orgánica del Poder Judicial y 146 del Código Electoral}

En el trabajo inicial, base de la continuidad de esta investigación, se había propuesto una modificación como medida para ampliar el rango de servidores que participan. Consistía en que la restricción aplicara según el examen de responsabilidades de cada puesto, tomando en cuenta la posición de toma de decisiones, el contacto continuo con expedientes e información confidencial, así como la posible relación con la esfera política.

Inicialmente, se había elaborado una lista taxativa de servidores a los que debía continuar aplicándoseles la prohibición por considerarse que podían tener injerencia en el proceso electoral, según el examen de responsabilidades señalado. A mayor grado de responsabilidades se iban sumando puestos a la lista.

Se incluyó a los siguientes funcionarios: servidores del ámbito jurisdiccional, Ministerio Público, Organismo de Investigación Judicial, Corte Plena, Consejo Superior, Dirección Ejecutiva y Presidencia de la Corte Suprema de Justicia. Se planteó que esos cargos debían seguir impedidos en virtud de ser los que tienen contacto directo y continuo con los expedientes en su trámite y resolución. Además, se valoraron los principios de imparcialidad y objetividad que recaen sobre ellos y se incluyó a la alta jerarquía del sector administrativo por ser los representantes externos de la institución (Lara y Sánchez, 2016). 


\section{DERECHO ELECTORAL}

Sin embargo, se ha reflexionado al respecto y actualmente se evalúa una nueva postura mediante la eliminación por completo de la restricción y permitir a los servidores judiciales realizar actividades de carácter políticoelectoral, ya que como menciona Ricardo Salas "este tipo de prohibiciones, lo que pretenden es asegurar la credibilidad, no la garantizan, la credibilidad se puede perder con ellas o sin ellas, y también se puede conservar con ellas o sin ellas" (Comunicación personal, 6 de agosto de 2015).

En palabras de Salas:

Existe un propósito que se encuentra claramente definido en la Ley General de la Administración Pública [en adelante, "LGAP"]: hay un servicio público, que es gratuito y neutral. Si un funcionario comete un acto inapropiado, que colisiona con el ordenamiento administrativo, debe abrírsele una causa disciplinaria y si se trata de un delito, acudir a la jurisdicción penal como corresponde. (Comunicación personal, 6 de agosto de 2015)

Esto puede relacionarse con el criterio de que cuanto más transparente sea el funcionario judicial, más confianza crea y de previo se conoce claramente la ideología política que prefiere. De esta manera, cualquier usuario del servicio judicial conocería de antemano a qué "tipo" de administrador de justicia se enfrenta, a qué posiciones tiende, cómo resuelve, etc.

A pesar de que el sistema judicial pretenda que imperen los principios de imparcialidad y objetividad en los funcionarios judiciales y principalmente, en los jueces y magistrados, no puede negarse que se trata de seres humanos que toman posturas frente a distintos temas, se inclinan a ciertas ideologías e impregnan sus resoluciones de esa forma de pensar.

En ese orden de ideas, puede decirse que es posible medir a los jueces en virtud de las perspectivas que dejan plasmadas en sus sentencias y la posición que tienen acerca de temas controversiales como el aborto, unión entre parejas del mismo sexo, estado laico, política criminal, etc. Asimismo, pueden identificarse patrones en otro tipo de funcionarios, independientemente de la función que realicen, pues como se ha venido indicando, antes de servidores judiciales, son personas como cualquier ciudadano que adquieren diferentes posiciones respecto de ciertos temas.

Ahora bien, es fundamental tener claro que el hecho de que un funcionario público se adhiera a una posición, ideología o partido político, inclusive, no significa que automáticamente se convierte en un servidor corrupto o 


\section{DERECHO ELECTORAL}

antiético, pues para ello es necesario que incurra en algún delito o falta administrativa. Ante esas eventualidades, se encuentran las sanciones correspondientes.

En virtud de que lo mencionado es innegable e imposible de evitar, considero que con mucha mayor razón es necesario eliminar las restricciones existentes (específicamente las contenidas en el artículo 9 de la LOPJ y el $146 \mathrm{CE}$ ) y habilitar a la población judicial en el disfrute de sus derechos fundamentales de carácter político-electoral, lo cual debe llevarse a cabo mediante la reforma de la ley, según lo señalado. A través de esta propuesta de reforma lo que se pretende es autorizar a los funcionarios del Poder Judicial a ejercer los derechos políticos que actualmente tienen vedados, pues como se ha señalado la restricción resulta desactualizada y lesiva de derechos fundamentales y, además, ha quedado demostrado que los afectados tienen interés en participar de una manera más activa en los procesos electorales.

Ahora bien, como se ha venido indicando a lo largo del presente artículo, la propuesta es modificar los numerales mediante una fórmula sencilla y clara que resulte acorde con el texto constitucional, a efectos de que no exista duda de cuál es realmente la prohibición que recae sobre los servidores judiciales, pues a pesar de todo lo anterior deben apegarse al principio de legalidad. Realizada esa salvedad, en adelante se expone una propuesta inicial del nuevo texto de los incisos 5 y 6 del numeral 9 de la ley para que sea en esta línea:

"Artículo 1.-: Refórmense los incisos 5 y 6 del artículo 9 de la Ley Orgánica del Poder Judicial, ley número 8 del 29 de noviembre de 1937. Los textos dirán:

Artículo 9.-: Se prohíbe a todos los funcionarios y empleados del Poder Judicial:

5.- La utilización de su cargo para beneficiar a partidos políticos y/o candidatos, o para influenciar a otros funcionarios a que lo hagan. 6.- Tomar parte activa en reuniones, manifestaciones y otros actos de carácter político electoral o partidista, durante su jornada laboral. (...)

A estos funcionarios solamente se les aplicarán las restricciones contenidas en el párrafo primero del artículo 146 del Código Electoral. 


\section{DERECHO EIECTORAL}

Respecto al artículo 146 del Código Electoral, la modificación propuesta consistiría en una supresión de los servidores judiciales contemplados en la lista de funcionarios públicos mencionados en el párrafo segundo, de manera que quedaría de la siguiente forma:

"Artículo 2: Refórmese el párrafo segundo del artículo 146 del Código Electoral, ley número 8765 del 2009. Su nuevo texto dirá:

Quienes ejerzan la Presidencia o las Vicepresidencias de la República, los ministros(as) y viceministros(as), y los miembros activos o las miembros activas del servicio exterior, el contralor o la contralora y subcontralor o subcontralora generales de la República, el (la) defensor(a) y el (la) defensor(a) adjunto(a) de los habitantes, el (la) procurador(a) general y el (la) procurador(a) general adjunto(a), quienes ejerzan la presidencia ejecutiva, o sean miembros(as) de las juntas directivas, directores ejecutivos, gerentes y subgerentes de las instituciones autónomas y todo ente público estatal, los(as) oficiales mayores de los ministerios, los(as) miembros (as) de la autoridad de policía, los magistrados(as) y toda persona empleada del TSE, y quienes tengan prohibición en virtud de otras leyes, no podrán participar en las actividades de los partidos políticos, asistir a clubes ni reuniones de carácter político, utilizar la autoridad o influencia de sus cargos en beneficio de los partidos políticos, colocar divisas en sus viviendas o vehículos, ni hacer ostentación partidista de cualquier otro género.

Por tratarse de un primer acercamiento a lo que más adelante podría convertirse en un proyecto de ley, dicho contenido está sujeto a estudio, revisiones y modificaciones $\mathrm{y}$, por tanto, a cualquier reconsideración necesaria para mejorar el texto propuesto, a fin de que resulte claro, efectivo y garante de los derechos de la población judicial, sin afectar de forma alguna el principio de pureza electoral. 


\section{DERECHO ELECTORAL}

\section{REFERENCIAS BIBLIOGRÁFICAS}

Lara, D. y Sánchez, C. (2016) Restricción generalizada a la participación política de los servidores judiciales (tesis de licenciatura). Universidad de Costa Rica, San José, Costa Rica.

Corte Interamericana de Derechos Humanos (2008). Caso Castañeda Gutman Vs. México. Excepciones Preliminares, Fondo, Reparaciones y Costas. Sentencia del seis de agosto.

Sala Constitucional (2014). Voto 868-2014 de las catorce horas con treinta minutos del veintidós de enero.

Tribunal Supremo de Elecciones (2000). Voto 1310-1-E-2000 de las quince horas con cincuenta minutos del veintisiete de junio.

Tribunal Supremo de Elecciones (2000). Voto 1394-E-2000 de las nueve horas con quince minutos del once de julio.

Tribunal Supremo de Elecciones (2001). Voto 2071-E-2001 de las nueve horas con cuarenta minutos del nueve de octubre.

Tribunal Supremo de Elecciones (2007). Voto 1119-E-2007 de las catorce horas con veinte minutos del diecisiete de mayo.

Tribunal Supremo de Elecciones (2008). Voto 472-E8-2008 de las siete horas con cincuenta minutos del trece de febrero.

Tribunal Supremo de Elecciones (2012). Voto 3820-E8-2012 de las catorce horas con cincuenta minutos del veintiuno de mayo.

Tribunal Supremo de Elecciones (2018). Voto 1728-E8-2018 de las trece horas con diez minutos del diecinueve de marzo. 